\title{
Determining the Burden of Neurological Disorders in Populations Living in Tropical Areas: Who Would Be Questioned? Lessons from a Mexican Rural Community
}

\author{
Fabrice Quet $^{\mathrm{a}}$ Pierre-Marie Preux ${ }^{\mathrm{a}}$ Mirna Huerta ${ }^{\mathrm{b}}$ Ruben Ramirez ${ }^{\mathrm{c}}$ \\ Teresa Abad $^{b}$ Gladis Fragoso $^{c}$ Julio Morales ${ }^{c}$ Edda Sciutto $^{c}$ Agnès Fleury $^{c, d}$ \\ aIFR 145 GEIST, Institut d'Epidémiologie Neurologique et de Neurologie Tropicale, EA 3174 Neuroepidémiologie \\ Tropicale et Comparée, Université de Limoges, Limoges, France; ${ }^{b}$ Facultad de Medicina, Benemérita Universidad \\ Autónoma de Puebla, Puebla, y ${ }^{C}$ Instituto de Investigaciones Biomédicas, Universidad Nacional Autónoma de \\ México, y ${ }^{\mathrm{d}}$ Instituto Nacional de Neurología y Neurocirugía, México, México
}

\section{Key Words}

Latin America • Prevalence study, questionnaires •

Headache $\cdot$ Neuropathy $\cdot$ Epilepsy

\begin{abstract}
Background: The best approach to determine the burden of neurological disorders in developing countries is to perform population-based studies. Our objectives were to determine the prevalence of neurological disorders in a Mexican rural community and assess the usefulness of a household screening questionnaire. Methods: The survey took place in a Mexican rural community of Puebla State in Mexico. This was a cross-sectional, population-based, 2-phase study including a comparison of the usefulness levels of the individual (IQ) and household (HQ) questionnaires. Results: A total of 4,008 individuals participated in the prevalence study using the IQ; of these, 280 neurological examinations allowed to identify 127 individuals suffering from at least 1 neurological disease. The most frequent ailments were headache $(22.4 / 1,000,95 \%$ confidence interval, $\mathrm{Cl}$ : 17.7-28.2), neuropathy $(7.1 / 1,000, \mathrm{Cl}$ 95\%: 4.4-11.3) and epilepsy (3.9/1,000, Cl 95\%: 2.3-6.5). The
\end{abstract}

$H Q$, used in parallel with the $I Q$, detected significantly fewer neurological cases. This result was mainly due to the low capacity of the HQ to detect headache. Conclusions: Results of the prevalence study are discussed emphasizing their relevance in adequately allocating resources. The usefulness of the HQ for screening neurological disorders in general was low, but could be adequate for specific neurological disorders.

Copyright $\odot 2011$ S. Karger AG, Basel

\section{Introduction}

Worldwide, epidemiological studies on neurological disorders (ND) are mostly based on hospital and autopsy records [1]. These studies are somewhat biased, particularly in developing countries, where not all the population has access to the public health system and no mandatory reporting practice exists. Over the last 3 decades, population-based studies directed to determine the true burden of ND have been increasingly acknowledged. Nevertheless, in developing countries, the limited access

\section{KARGER}

Fax +4161306 1234 E-Mail karger@karger.ch www.karger.com
(C) 2011 S. Karger AG, Basel

0251-5350/11/0363-0194\$38.00/0

Accessible online at:

www.karger.com/ned
Agnès Fleury, Instituto de Investigaciones Biomédicas

Instituto Nacional de Neurología y Neurocirugía

Insurgentes Sur 3877, Colonia la Fama, Delegación Tlalpan

México, DF 14269 (México)

Tel. +52 555606 3822, ext. 2052, E-Mail afleury@biomedicas.unam.mx 
of neurologists to rural areas and the logistic and economic limitations to perform neuroepidemiological studies have significantly complicated their implementation [2-4]. To the best of our knowledge, only 4 population-based neuroepidemiological studies have been carried out in Mexico. Only one of these is a general neuroepidemiological study directed to determine the main ND prevalence, and in it, a questionnaire was applied to the household leader (household questionnaire, HQ) during the screening phase [5]. The other 3 studies were more specifically focused on only 1 ND (epilepsy, migraine or headache) [6-8]. General neuroepidemiological studies directed to evaluate the global burden of ND in a population are thus still required to orient public health investigations and interventions.

The present study was designed according to the World Health Organization protocol [9] to determine ND prevalence in a rural community of central Mexico and to evaluate the usefulness of an HQ. In neuroepidemiological studies, each studied subject normally answers the questionnaire personally during the screening phase, which implies high logistic and time costs. The method tested herein could be of particular interest to be used in general neuroepidemiological surveys in areas with poor resources.

\section{Methods}

\section{Study Design}

A 2-phase study design was adopted to determine the ND prevalence, consisting in the application of the WHO screening questionnaire for ND by trained field interviewers followed by a clinical examination of the subjects by neurologists. To compare the individual questionnaire (IQ) and HQ, they were simultaneously and independently applied to each household during the screening phase. The household leader was considered as the family member best informed about the health situation of each of the family.

\section{Study Area and Population}

San-Andrés Azumiatla (latitude $18^{\circ} 53^{\prime}$ and $18^{\circ} 54^{\prime} \mathrm{N}$, longitude $98^{\circ} 14^{\prime}$ and $98^{\circ} 16^{\prime} \mathrm{W}$ ) is a Mexican rural community located 30 min away from the city of Puebla. Prior to this study, a census was carried out to evaluate the main characteristics of the community (unpublished data from the CECACVI, Nursing Academy Center). According to the census, San-Andrés Azumiatla has a total population of 6,203 inhabitants (1,190 households) mostly of Nahuatl origin. The population is predominantly young $(43.0 \%$ are under $16,83.6 \%$ are under 40 ). Education level and family income are low: $23.0 \%$ of the population is illiterate, and $42.4 \%$ completed primary education only; $88.1 \%$ of the population earns less than 2 minimum salaries per family ( $<7.0$ US dollar/day). Water distribution could be substantially improved: although $89.5 \%$ of the population has a running water supply, it is chlorinated in only $33.5 \%$ of the network. On the other hand, $66.5 \%$ of the population does not own latrines, and $85.5 \%$ are not connected to the sewage. The health care infrastructure consists of a rural health center and an academic center used by nursing students for practice.

Although the studied community is located near an important urban area, its members have close family relationships: $97 \%$ of the population was born in San-Andrés Azumiatla, and only 3 surnames are present in $46 \%$ of the population as first or second names. Inhabitants were included as subjects of this study only if they had been living in San-Andrés Azumiatla for at least the 6 months preceding the survey. The local and state authorities were informed and gave their agreement and logistic support. The study was approved by the Ethical Committee of the Instituto Nacional de Neurología y Neurocirugía, México.

\section{Screening Phase}

Information was obtained from a total of 1,006 of the 1,190 households of the community.

Individual Questionnaire

San-Andrés Azumiatla was screened door to door, in order to identify people who had suffered or presently suffer from ND (lifetime prevalence). The WHO IQ was initially applied, which includes 12 standardized questions and 4 simple tasks for a quick evaluation of motor or sensitive deficit, tremor and ataxia. Four more questions were added to improve sensitivity regarding epilepsy, psychomotor delay, diplopia and memory failure. The questionnaire was automated using an MS Access application.

Household Questionnaire

In order to assess the validity of the household leader's responses, an HQ was designed based on the IQ. This instrument consists of exactly the same questions as the IQ, but omits the simple tasks. The HQ was applied independently on a paper sheet.

\section{Methodology}

The field interviewers in charge of the screening were medical, nursing and veterinary students, trained for 3 days before the study in order to minimize inter- and intraobserver variations. The training included a brief presentation of ND, recommendations on epidemiological surveys, interview role plays and the use of the MS Access application. Field interviewers were divided into 13 teams of 3 members each; each team included a nursing student with knowledge of the community who facilitated contact with the inhabitants. The community was divided into 6 sectors and 97 blocks. Each team of field interviewers was assigned a different group of blocks every morning. Interviews were organized as follows: the team of field interviewers arrived at a house and identified the household leader; 1 interviewer applied the HQ to the household leader and wrote down a list of all the household inhabitants, present or absent; the 2 remaining interviewers applied the IQ to all inhabitants present in the household. Computerized data from the IQ applied by each team were saved daily, as well as the HQ sheets, which were collected and stored until recording. A database was built which included all the information. Subjects who answered 'yes' to one of the questions or were unable to perform any of the simple tasks were considered as 'suspect' of suffering from ND. 


\section{Neurological Examination}

A neurological examination was applied to all subjects who were classified as 'suspects' during the screening phase. This was performed by a certified neurologist or by a neurology student concluding residency who was always supervised by a neurologist. Confirmed neurological patients who required follow-up were referred to the General Hospital of the city of Puebla.

\section{Diagnostic Criteria}

Headaches were diagnosed based on the definitions proposed by the International Headache Society in 2004 [10]. Epilepsy was diagnosed according to the epidemiological definition proposed by the International League against Epilepsy in 1993 [11]. Stroke was diagnosed based on the definition proposed by the WHO as a condition characterized by rapidly developing symptoms and signs of a focal brain lesion, with symptoms lasting for more than $24 \mathrm{~h}$, with no other apparent cause than ones of vascular origin [12]. Diagnosis of peripheral nerve disorders was based on at least 2 of the following criteria: (a) muscle weakness and distal wasting; (b) reduced or absent deep tendon reflexes; (c) sensory deficits specific in type and distribution [13]. Bell's palsy was diagnosed specifically by the acute onset of unilateral or bilateral paralysis of the facial expression muscles as a result of a lower motor neuron lesion of the facial nerve, and for which no definite etiology was identified [14]. Psychomotor delay was diagnosed upon observation of global delay in cognitive and motor learning, excluding dyslexia, with onset before the age of 18 years and at least 2 of the following: limitation in self-care, home living, social skills, community use, self-direction, health and safety, leisure and work associated with deficits or impairments in communication and self-care, and home living (DSM-IV) [15]. Diagnoses were based on clinical grounds without psychometric evaluation. Cerebellar disorders were diagnosed on the basis of the presence of at least 3 of the following criteria: gait ataxia, intention tremor, adiadochokinesis, dysmetria and dysarthria. Diagnosis of essential tremor was based on the consensus statement of the Movement Disorder Society [16]. Dementia was diagnosed when memory impairment existed associated with 1 of the following features: aphasia, apraxia, agnosia or disturbances in executive functioning, in the presence of a state of clear consciousness [15]. Head trauma and central nervous system infection (virus, bacteria, fungus or parasite) were considered as the cause of a permanent brain damage leading to a neurological incapacity. They were ascertained by the natural history of the patient and, when available, by their radiological studies.

\section{Data Management and Statistical Analysis}

Merging, updating, pooling and verifying the quality of data was done using the MS Access Software. Statistical analyses were performed with the following softwares: Statview 5.0 (SAS Institute Inc., Cary, N.C., USA), Medcalc 9.4.2.0 (Medcalc Software, Mariakerke, Belgium) and SPSS 10 (SPSS Inc. Headquarters, Chicago, Ill., USA). Crude and standardized prevalences on the world population were calculated (as described by Segi [17]). Quantitative variables were expressed as mean and standard deviation, and compared using the two-tailed Student t test or the Mann-Whitney test. Qualitative variables were expressed in percentages with $95 \%$ confidence intervals (CI) and compared using the $\chi^{2}$, MacNemar or Fisher's exact tests. Concordance between questionnaires was estimated using the kappa coefficient with $95 \%$ CI. The level of significance was 0.05 .

\section{Results}

The general design of the survey is shown in figure 1. Information from 1,005 households of 1,190 identified during the census was obtained. 185 families (15.5\%) were not interviewed, either because they refused to participate or because they could not be contacted during the screening phase, despite repeated attempts. The HQ was applied to 1,005 household leaders of the families included in this study and allowed collecting data from a total of 5,195 subjects (fig. 1). Of these, 4,008 subjects were also screened by the IQ. Age and sex distribution of this sample is shown in table 1. Compared with the entire community, our sample was similar in age, although the masculine gender was underrepresented $(p<0.0001)$. The 1,187 subjects only screened by the HQ were absent during the screening phase and could not be contacted later. In 2 cases, the household leader gave the answer 'I don't know', and they were thus omitted from analyses.

\section{Concordance between IQ and HQ}

To assess the usefulness of the HQ, results obtained from 4,006 subjects evaluated by both questionnaires were compared. Concordance between the two questionnaires regarding suspected cases was determined (table 2a). A kappa coefficient of 0.69 (95\% CI: 0.65-0.74) was obtained.

The usefulness of the IQ and HQ regarding the detection of confirmed neurological cases was evaluated (table $2 \mathrm{~b}$ ). As shown in this table and in figure 1, the HQ alone allowed the diagnosis of 16 neurological cases corresponding to $18 \mathrm{ND}$. Of these cases, 12 were not detected by the IQ ( 5 cases of headache, 3 of neuropathy, 2 of psychomotor delay, 1 of epilepsy and 1 case of headache associated with neuropathy), and 4 were not evaluated by the IQ (1 case of headache, 1 of essential tremor, 1 of cerebellar ataxia and 1 of cerebellar ataxia associated with epilepsy). The IQ detected significantly $(\mathrm{p}<0.0001)$ more patients $(127 / 143,88.8 \%)$ than the HQ (73/143, 51.0\%). This difference was mainly due to the poor capacity of the HQ to detect headaches: the IQ detected 74 of the 81 patients with headache (91.4\%), while the HQ detected only 28 (34.6\%; $\mathrm{p}<0.0001)$. No further differences were found in questionnaires considering the remaining ND separately. The IQ and HQ detected each one 19 of the 24 neuropathies (79.2\%). Regarding epilepsy, the IQ detected 16 of the 18 cases (88.9\%) while the HQ detected 12 (66.7\%). However, the usefulness of questionnaires remained significantly different when all ND excluding headaches were considered. In this case, the IQ detected 60 of the 70 
Fig. 1. General design of the survey. Light gray: results of prevalence study; light and dark gray: results used to compare the questionnaires' usefulness.

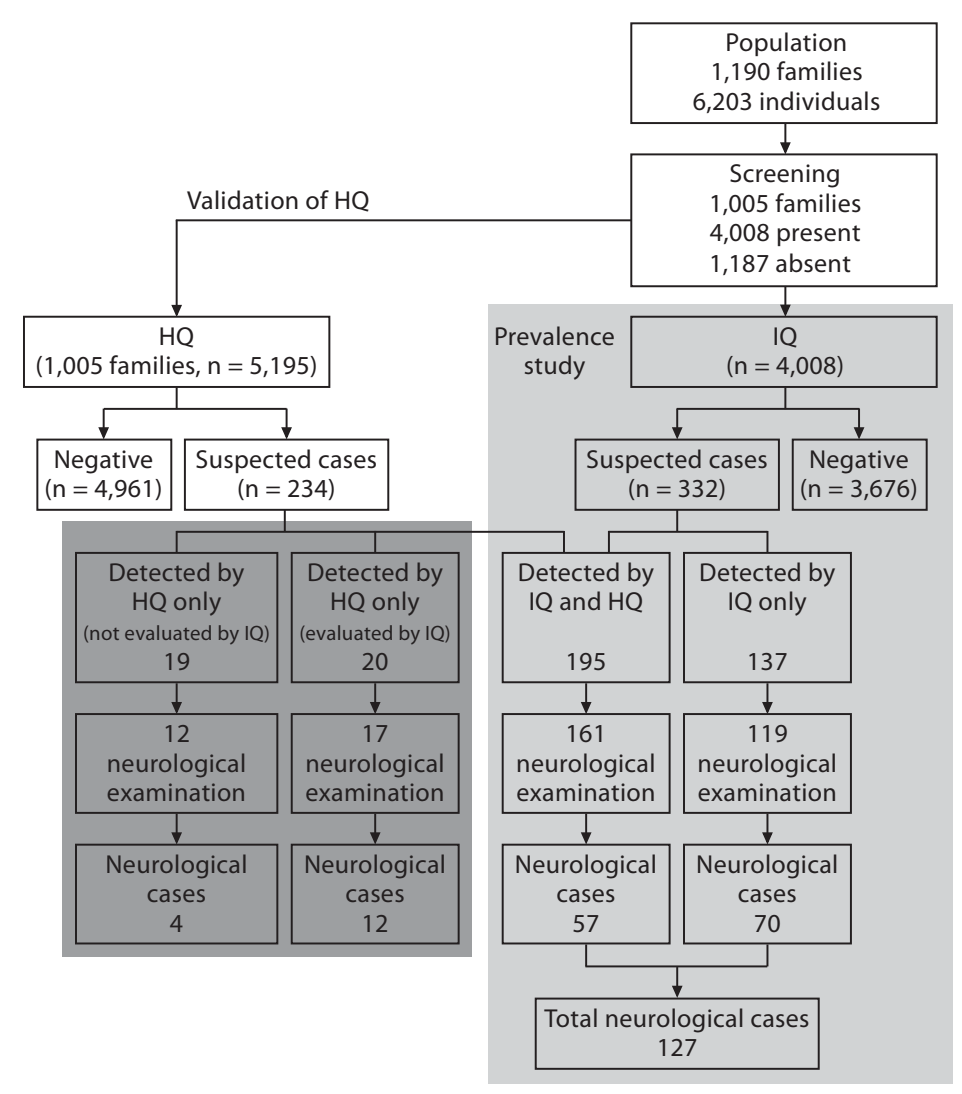

$\mathrm{ND}(85.7 \%)$ while the HQ detected 47 of the $70 \mathrm{ND}$ (67.1\%; $\mathrm{p}=0.037)$.

\section{Prevalence Studies}

Prevalence Determined by the IQ

In this analysis, a total of 4,008 inhabitants $(64.8 \%$ of the population) was included in the study (fig. 1). During the screening phase, 332 inhabitants $(8.3 \%)$ appeared as 'suspects' of ND. A total of 280 neurological consultations were performed, which identified 127 neurological patients. In addition, 10 of these subjects presented $2 \mathrm{ND}$, which gave a total of 137 neurological pathologies. Crude and standardized prevalence rates and age-specific prevalence distribution of ND are presented in table 3 and figure 2 , respectively. In table 4 , age- and sex-specific prevalence rates for the 3 main ND are shown.

Headache was the most frequent symptom $(18.5 / 1,000$, 95\% CI: 14.6-23.3), followed by peripheral nerve diseases (4.7/1,000, 95\% CI: 2.9-7.5) and epilepsy (4.0/1,000, 95\% CI: 2.4-6.6). Headache prevalence was higher in subjects
Table 1. Age and sex distribution of the subjects surveyed by the IQ, San-Andrés Azumiatla, Mexico, 2007

\begin{tabular}{lccc}
\hline Age & Men & Women & Both sexes \\
\hline 0-15 years & $870(50.2)$ & $948(41.9)$ & $1,818(45.5)$ \\
16-40 years & $550(31.8)$ & $933(41.2)$ & $1,483(37.1)$ \\
$41-60$ years & $212(12.2)$ & $276(12.2)$ & $488(12.2)$ \\
$>60$ years & $100(5.8)$ & $107(4.7)$ & $207(5.2)$ \\
\hline Total $^{1}$ & $1,732(43.3)$ & $2,264(56.7)$ & $3,996(100.0)$
\end{tabular}

Results are numbers, with percentages in parentheses.

${ }^{1}$ Age was not determined in 12 cases.

of both sexes from 41 to 60 years of age, and was significantly higher in women than in men aged 16-60 years. Of the 74 cases of headache, 25 were diagnosed as migraine (20 cases in women and 5 in men, global prevalence of $6.2 / 1,000,95 \%$ CI: 4.1-9.3), 40 were diagnosed as 
Fig. 2. Age-specific prevalences of the different neurological pathologies.

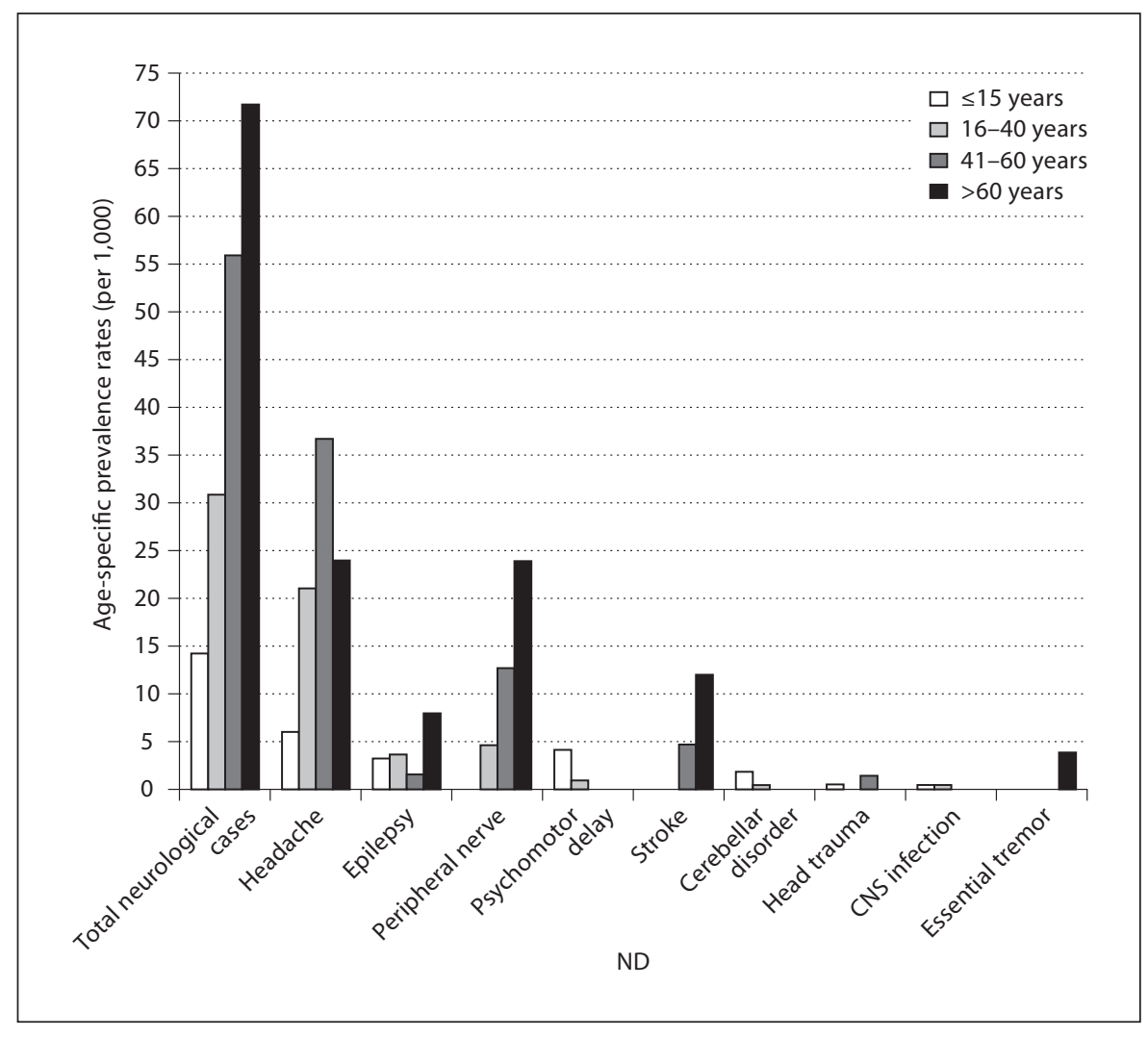

tension headache (32 cases in women and 8 in men, global prevalence of 10.0/1,000, 95\% CI: 7.2-13.7) and 9 were primary headache ( 1 man and 8 women, global prevalence of 2.2/1,000, 95\% CI: 1.1-4.4). Epilepsy was more frequent in subjects under 40 years of age. Of the 16 cases, 12 had generalized tonic-clonic seizures, 3 had complex partial seizures and 1 had complex partial seizures with secondary generalization. Only 4 subjects were receiving treatment (carbamazepine, valproic acid, clonazepam). The prevalence of neuropathies increased with age and did not differ between sexes. Of the 6 inhabitants with stroke, 5 probably had an ischemic event while 1 had a hemorrhagic stroke. Two subjects had got a CT scan that confirmed diagnosis. Cases of cerebellar syndromes were diagnosed in 2 families (fig. 3). Three siblings were affected in 1 of these families, and 2 sisters and 1 cousin were affected in the other.

Prevalence Determined by the HQ

We also determined the prevalence of ND considering only the HQ. Crude and standardized prevalences estimated by this way are presented in table 3 .
Table 2. Concordance between questionnaires, for suspected and confirmed neurological cases

a Concordance between IQ and HQ to detect cases suspected of neurological diseases

\begin{tabular}{|c|c|c|c|}
\hline \multirow[t]{2}{*}{ HQ } & \multicolumn{3}{|l|}{ IQ } \\
\hline & suspect & normal & total \\
\hline Suspect & 195 & 20 & 215 \\
\hline Normal & 137 & 3,654 & 3,791 \\
\hline Total & 332 & 3,674 & $4,006^{1}$ \\
\hline
\end{tabular}

b Concordance between IQ and HQ to detect confirmed neurological cases

\begin{tabular}{llll}
\hline HQ & IQ & & \\
\cline { 2 - 4 } & positive & negative & total \\
\hline Positive & 57 & 12 & $69(49.6)$ \\
Negative & 70 & 0 & $70(50.4)$ \\
\hline Total & $127(88.8)$ & $12(11.2)$ & $139(100.0)$
\end{tabular}

Results are numbers; figures in parentheses indicate percentages; kappa coefficient $=0.69$ (95\% CI: 0.65-0.74).

${ }^{1}$ Individuals screened by both IQ and HQ. 
Table 3. Crude and standardized prevalence rates of neurological disorders, from the sample of population surveyed by the IQ and HQ, San-Andrés Azumiatla, Mexico, 2007

\begin{tabular}{|c|c|c|c|c|c|c|c|c|c|c|}
\hline \multirow[t]{2}{*}{ ND } & \multicolumn{5}{|l|}{ IQ } & \multicolumn{5}{|c|}{ HQ } \\
\hline & $\mathrm{n}$ & $\begin{array}{l}\text { crude } \\
\text { prevalence } \\
\text { per } 1,000\end{array}$ & $95 \% \mathrm{CI}$ & $\begin{array}{l}\text { standardized } \\
\text { prevalence } \\
\text { per } 1,000\end{array}$ & $95 \% \mathrm{CI}$ & $\mathrm{n}$ & $\begin{array}{l}\text { crude } \\
\text { prevalence } \\
\text { per } 1,000\end{array}$ & $95 \% \mathrm{CI}$ & $\begin{array}{l}\text { standardized } \\
\text { prevalence } \\
\text { per } 1,000\end{array}$ & $95 \% \mathrm{CI}$ \\
\hline Headache & 74 & 18.5 & $14.6-23.3$ & 22.4 & $17.7-28.2$ & 28 & 5.4 & $3.7-7.9$ & 7.1 & $5.6-8.9$ \\
\hline Neuropathy & 19 & 4.7 & $2.9-7.5$ & 7.1 & $4.4-11.3$ & 19 & 3.7 & $2.3-5.8$ & 5.6 & $4.3-7.3$ \\
\hline Epilepsy & 16 & 4.0 & $2.4-6.6$ & 3.9 & $2.3-6.5$ & 12 & 2.3 & $1.3-4.2$ & 2.2 & $0.7-2.1$ \\
\hline Psychomotor delay & 9 & 2.2 & $1.1-4.4$ & 1.7 & $0.8-3.3$ & 7 & 1.3 & $0.6-2.9$ & 1.1 & $0.3-1.5$ \\
\hline Stroke & 6 & 1.5 & $0.6-3.4$ & 2.9 & $1.2-6.6$ & 3 & 0.6 & $0.1-1.8$ & 1.1 & $0.1-1.0$ \\
\hline Cerebellar disorder & 2 & 0.5 & $0.1-2.0$ & 0.3 & $0.1-1.4$ & 3 & 0.6 & $0.1-1.8$ & 0.5 & $0.1-1.0$ \\
\hline Head trauma & 2 & 0.5 & $0.1-2.0$ & 0.6 & $0.1-2.4$ & 1 & 0.2 & $0.0-1.2$ & 0.1 & $0.0-0.6$ \\
\hline CNS infections & 2 & 0.5 & $0.1-2.0$ & 0.4 & $0.1-1.7$ & 1 & 0.2 & $0.0-1.2$ & 0.2 & $0.0-0.6$ \\
\hline Essential tremor & 1 & 0.5 & $0.1-2.0$ & 0.5 & $0.0-3.4$ & 1 & 0.2 & $0.0-1.2$ & 0.4 & $0.0-0.6$ \\
\hline Total of cases & 127 & 31.7 & $26.6-37.7$ & 42.0 & $35.5-49.6$ & 73 & 14.1 & $11.1-17.7$ & 18.0 & $11.3-27.2$ \\
\hline
\end{tabular}

$\mathrm{n}=$ The total number of ND is higher than the total number of cases since some patients presented 2 neurological diseases; standardized prevalence: standardization with respect to the world population [17].

Table 4. Age- and sex-specific prevalence rates of the main neurological diseases, from the sample of population surveyed by the IQ, San-Andrés Azumiatla, Mexico, 2007

\begin{tabular}{|c|c|c|c|c|c|c|c|c|c|c|c|c|c|}
\hline \multirow[t]{2}{*}{ Age group } & \multirow[t]{2}{*}{ Sex } & \multicolumn{3}{|c|}{ Headache } & \multicolumn{3}{|c|}{ Neuropathy } & \multicolumn{3}{|c|}{ Epilepsy } & \multicolumn{3}{|c|}{ Total neurological cases } \\
\hline & & $\mathrm{n}$ & $\begin{array}{l}\text { prevalence } \\
\text { per } 1,000\end{array}$ & $95 \% \mathrm{CI}$ & $\mathrm{n}$ & $\begin{array}{l}\text { prevalence } \\
\text { per } 1,000\end{array}$ & $95 \%$ CI & $\mathrm{n}$ & $\begin{array}{l}\text { prevalence } \\
\text { per } 1,000\end{array}$ & $95 \%$ CI & $\mathrm{n}$ & $\begin{array}{l}\text { preval } \\
\text { per } 1,0\end{array}$ & $95 \%$ CI \\
\hline \multirow[t]{3}{*}{$\leq 15$ years } & M & 4 & 4.6 & $1.4-12.5$ & 0 & - & - & 4 & 4.6 & $1.4-12.5$ & 13 & 14.9 & $8.3-26.1$ \\
\hline & $\mathrm{F}$ & 9 & 9.5 & $4.6-18.6$ & 0 & - & - & 3 & 3.2 & $0.8-10.0$ & 15 & 15.8 & $9.2-26.6$ \\
\hline & $\mathrm{T}$ & 13 & 7.2 & $4.0-12.5$ & 0 & - & - & 7 & 3.9 & $1.7-8.3$ & 28 & 15.4 & $10.5-22.5$ \\
\hline \multirow[t]{3}{*}{$15-40$ years } & M & 5 & $9.1^{1}$ & $3.4-22.4$ & 1 & 1.8 & $0.1-11.7$ & 3 & 5.4 & $1.4-17.2$ & 9 & $16.4^{1}$ & $8.0-32.0$ \\
\hline & $\mathrm{F}$ & 31 & $33.2^{1}$ & $23.1-47.4$ & 7 & 7.5 & $3.3-16.1$ & 4 & 4.3 & $1.4-11.7$ & 45 & $48.2^{1}$ & $35.8-64.5$ \\
\hline & $\mathrm{T}$ & 36 & 24.3 & $17.3-33.8$ & 8 & 5.4 & $2.5-11.1$ & 7 & 4.7 & $2.1-10.2$ & 54 & 36.4 & $27.7-47.6$ \\
\hline \multirow[t]{3}{*}{$41-60$ years } & M & 4 & $18.9^{1}$ & $6.1-50.8$ & 2 & 9.4 & $1.6-37.6$ & 0 & - & & 7 & $33.0^{1}$ & $14.5-69.6$ \\
\hline & $\mathrm{F}$ & 17 & $61.6^{1}$ & $37.4-98.6$ & 5 & 18.1 & $6.7-44.2$ & 1 & 3.6 & $0.2-23.2$ & 25 & $90.6^{1}$ & $60.6-132.4$ \\
\hline & $\mathrm{T}$ & 21 & 43.0 & $27.5-66.1$ & 7 & 14.3 & $6.3-30.7$ & 1 & 2.0 & $0.1-13.2$ & 32 & 65.6 & $46.0-92.3$ \\
\hline \multirow[t]{3}{*}{$>60$ years } & M & 1 & 10.0 & $0.5-62.4$ & 3 & 30.0 & $7.8-91.5$ & 0 & - & & 5 & 50.0 & $18.6-118.3$ \\
\hline & $\mathrm{F}$ & 3 & 28.0 & $7.3-85.8$ & 1 & 9.3 & $0.5-58.5$ & 1 & 9.3 & $0.5-58.5$ & 8 & 74.8 & $35.2-146.4$ \\
\hline & $\mathrm{T}$ & 4 & 19.3 & $6.2-52.0$ & 4 & 19.3 & $6.2-52.0$ & 1 & 4.8 & $0.3-30.8$ & 13 & 62.8 & $35.3-107.4$ \\
\hline
\end{tabular}

$\mathrm{M}=$ Male; $\mathrm{F}=$ female; $\mathrm{T}=$ total. ${ }^{1}$ The differences in sex distribution were statistically significant in the age groups $15-40$ and $41-60$ years for headache $(\mathrm{p}=0.02$ and $\mathrm{p}=0.015$, respectively) and for total neurological cases $(\mathrm{p}=0.016$ and $\mathrm{p}=0.004$, respectively). 
Table 5. Results of ND prevalence levels (per 1,000) in general neuroepidemiological studies

\begin{tabular}{|c|c|c|c|c|c|c|c|c|c|c|c|}
\hline References & Country & Standardization & Sample size & $\mathrm{H}$ & $\mathrm{E}$ & $\mathrm{PD}$ & S & $\mathrm{N}$ & $\mathrm{T}$ & I & $\mathrm{CD}$ \\
\hline Osuntokun et al. [18] & Nigeria & no & 20,000 & $53.0^{1}$ & 5.3 & 0.1 & 0.6 & $2.5^{2}$ & & & 0.1 \\
\hline Longe and Osuntokun [19] & Nigeria & no & 2,925 & $63.2^{1}$ & 6.2 & 0.7 & 0.7 & 2.1 & & & 0.3 \\
\hline Al Rajeh et al. [20] & Saudi Arabia & no & 22,630 & 20.7 & 7.6 & 6.3 & 1.8 & & & & \\
\hline Saha et al. [21] & India & no & 20,842 & 8.7 & 3.6 & & 1.5 & 0.8 & & & \\
\hline Pradilla et al. [22] & Colombia & national & 8,910 & $71.2^{1}$ & 10.3 & & 19.9 & 8.5 & 6.4 & & \\
\hline Gourie-Devi et al. [23] & India & national & 102,557 & 9.7 & 8.3 & 1.2 & 2.6 & 1.0 & & 0.3 & \\
\hline Nicoletti et al. $[24,25]$ & Bolivia & world & 10,000 & & 12.3 & & 1.7 & & & & \\
\hline $\begin{array}{l}\text { Cruz-Alcalá and } \\
\text { Vázquez-Castellanos [5] }\end{array}$ & Mexico & no & $9,082^{3}$ & & 6.8 & & 4.5 & & & & \\
\hline Del Brutto et al. [26-28] & Ecuador & US population & 2,548 & & 10.8 & & 8.4 & & & & \\
\hline El Tallawy et al. [29] & Egypt & no & 62,583 & & 7.0 & & 5.6 & & & & 2.0 \\
\hline Present study & Mexico & world & 4,008 & 22.4 & 3.9 & 1.7 & 2.9 & 7.1 & 0.6 & 0.4 & 0.3 \\
\hline
\end{tabular}

Standardization $=$ Population used for standardization. $\mathrm{H}=$ Headache; $\mathrm{E}=$ epilepsy; $\mathrm{PD}=$ psychomotor delay; $\mathrm{S}=$ stroke; $\mathrm{N}=$ neuropathy; $\mathrm{T}$ = traumatism; $\mathrm{I}$ = infection; $\mathrm{CD}$ = cerebellar disorder.

${ }^{1}$ Migraine. ${ }^{2}$ Polyneuropathies were only considered. ${ }^{3}$ Assessed by an HQ.

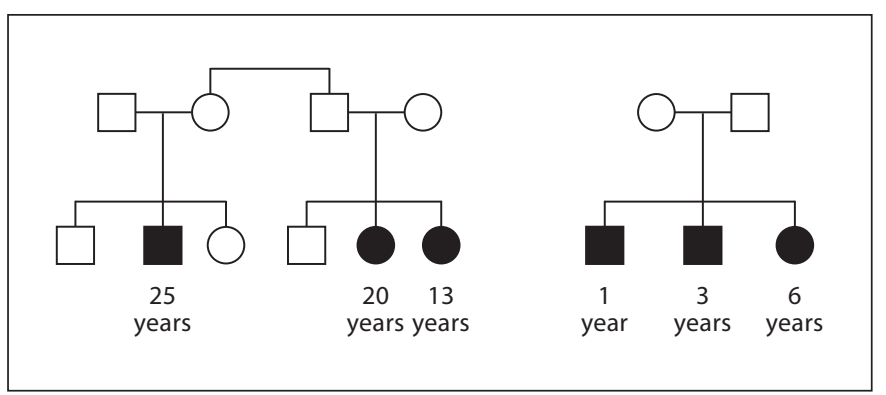

Fig. 3. Two families with multiple cases of cerebellar disorders.

\section{Discussion}

The WHO specified in 2006: 'The research agenda for developing countries needs to be developed to gain better understanding of the problem so that appropriate responses can be developed and evaluated. Specific areas for research and development could include conducting population-based epidemiological studies in developing countries where insufficient data limit evidence-based planning' [1]. Despite this statement, very few studies have been made. Table 5 resumes the main results of the available studies in tropical areas. It is important to note that the interest of such studies is not only to permit to evaluate contrasts across countries, but also within coun- tries, potentially identifying communities with elevated unknown risk factors and supporting public health investigations and interventions.

In Mexico, most neuroepidemiological data come from hospitals or autopsy-based studies with the wellknown associated biases. Easier ways for performing neuroepidemiological surveys could contribute to augment our knowledge about the situation in tropical areas.

We found that the sensitivity of the HQ to detect ND, considering globally 'all ND', was significantly lower than that of the individual questionnaire, although this difference, considering each disease separately, was only significant in the case of headache. This result may be expected, as headache is an 'invisible' disease, which is individually experienced by the patient. If headache is not considered, the sensitivity of the HQ increases, but not enough to cancel the significant difference between the questionnaires.

It is important to state that prevalences found using the IQ are probably overestimated due to a possible 'healthy worker effect' (the persons absent at the moment of the visit were probably working and in good health). Conversely, the HQ may underestimate prevalences due to its lower sensitivity, principally for the diagnosis of the more 'benign' neurological diseases. Choosing which tool to use will mainly depend on the objective of the study. The evident advantage of an HQ versus an IQ in terms of logistical organization is important to note. Ad- 
ditionally, its performances for the diagnosis of 'severe' ND seem to be very acceptable. Thus, if the main objective of a study is to determine the prevalence of severe ND, its utilization could be encouraged as suggested by Edwards et al. [30] in their work in Kenya. Nevertheless, as in the present study the number of patients per group was small, the certainty level of results is possibly low and further large-scale studies to fine-tune the differences between the HQ and the IQ must be supported. On the other hand, the traditional utilization of an IQ must be promoted if the main objective of a study is to give us a general panorama of ND in a community.

Regarding the prevalence of ND, headache, neuropathies and epilepsy were the 3 most frequent neurological pathologies, disregarding which questionnaire was used. It must be stated that inhabitants sampled by the IQ represent a small proportion of the population of the community (64.6\%) and were underrepresented in the masculine gender, facts that could generate some imprecision in the results. However, we found that headache was the most frequent neurological symptom. Our prevalence results are in accordance with results from other general neuroepidemiological studies (table 5) [5, 18-25], although the extreme heterogeneity of headache prevalence, ranging from 8.7 to $71.2 / 1,000$, must be noted. This great variability highlights the necessity to standardize tools and definitions in order to allow better analyses and comparisons of this highly heterogeneous ND. Cultural factors would also be taken into account in formulating questions, in order to be the most sensitive possible. The question used in the WHO questionnaire mentions 'episode of intense head pain' that can have a different meaning in different cultures.

Epilepsy prevalence $(3.9 / 1,000)$ was not significantly different from the other general neuroepidemiology study performed in Mexico [5], and similar to reports from developed countries [31]. Nevertheless, it is interesting to observe that this prevalence value was much lower than that reported in previous general neuroepidemiological studies from other Latin American countries such as Bolivia (12.3/1,000), Colombia $(10.3 / 1,000)$ and Ecuador $(10.8 / 1,000)$ and also than the prevalence reported in specific epidemiological studies $[22,24,28$, 32]. Here too, the high variability of the results, ranging from 6.0 to 42.3/1,000, must be mentioned. Methodological differences and socioeconomical factors may contribute to this difference. Thus, although the community studied in this work was of a very low socioeconomic level, it has access to a health center with a graduated medical doctor and a nurse training center. In
Mexico and Latin America, most community health centers are attended only by medical students or nurses. An unexpected finding of this study was the high frequency of neuropathies $(7.1 / 1,000)$. This prevalence was similar to the one found in the Colombian neuroepidemiological study; nevertheless, it is significantly higher than those of the other surveys. These high frequencies are probably related to the high prevalence of diabetes reported in Latin America and in populations of Native American descent [33]. Indeed, in Mexico, $7.5 \%$ of the adult population is diabetic, and the population with a lower degree of education and income is highly affected [34]. These data are in agreement with the worldwide rise of diabetes mellitus to epidemic proportions. Because of the magnitude of the problem, it has become a health priority in Mexico and has received progressively higher attention.

The finding of 2 families with young children and adolescents affected by cerebellar ataxia (fig. 3 ) is particularly dramatic. These patients require specialized attention, which cannot be obtained at the community's primary health care services. Furthermore, the family's limited income does not allow them to move to distant specialized centers. Thus, these patients turn down the possibility of being attended and are homebound with no possibility of rehabilitation. The parents of these affected persons do not know if they have any familial link, although they do share one of the surnames. Even if environmental or occupational factors could participate in the genesis of these diseases, a genetic origin is the first hypothesis as genetic ataxias are frequent in Mexico [35, 36]. Molecular studies to describe their origin are presently under way. These cases point at the need of implementing information campaigns and genetic counseling aimed at reducing these potentially preventable diseases.

In conclusion, regarding methodological issues, HQ performance levels were lower than IQ performance levels when all ND were considered. Nevertheless, its use for specific severe ND seems to be interesting and should be further evaluated. On the other hand, the results of this prevalence study show the importance of neuropathies, probably related to diabetes, for which preventive measures can be applied. Although epilepsy prevalence was relatively low, it was third in importance among ND in this community, and efforts to prevent it must be continued. This study also evidenced the problem of recessive genetic diseases that prevails in these closed communities. Here too, preventive measures must be applied. 


\section{Acknowledgements}

The authors are indebted to all the participants of this survey, particularly to the inhabitants of San-Andrés Azumiatla, the students (nurse, medical and veterinary specialties) from the Benemerita Universidad Autonoma de Puebla, Mexico, who took part in the door-to-door survey, and the authorities, neurologists and neurology residents from the Instituto Nacional de Neurología y Neurocirugía, Mexico, who assessed the neurological cases. Technical support was provided by the Instituto de Investigaciones Biomédicas from the Universidad Nacional Autónoma de México. The authors also thank Rosa Maria Galicia Aguilar and Maricarmen Moreno Tochihuitl, director and nurse coordinator of the nurse academic center of San-Andrés Azumiatla, and Dr. Virginia Rosales from the Rural Health Center for help with logistics throughout this study and for their useful knowledge of the community. English corrections were made by Isabel Pérez Montfort. This research was supported by the Instituto Cientifico Pfizer, Mexico, the program ECOS North/ANUIES (Evaluation-orientation de la Coopération Scientifique France - Amérique Latine, project M06S01), the doctoral school ED258 (Université de Limoges, France) and the Regional Council of the Limousin Region, France.

\section{Disclosure Statement}

No conflicts of interest.

\section{References}

1 World Health Organization: Neurological Disorders, Public Health Challenges. Geneva, World Health Organization, 2006.

-2 Bergen DC, World Federation of Neurology Task Force on Neurological Services: Training and distribution of neurologists worldwide. J Neurol Sci 2002;198:3-7.

3 World Health Organization, World Federation of Neurology: Atlas, Country Resources for Neurological Disorders. Geneva, World Health Organization, 2004.

4 4 Quet F, Odermatt P, Preux PM: Challenges of epidemiological research on epilepsy in resource-poor countries. Neuroepidemiology 2008;30:3-5.

5 Cruz-Alcalá LE, Vázquez-Castellanos JL: Prevalencia de algunas enfermedades neurológicas en la Ciudad de Tepatitlán, Jalisco, México. Rev Mex Neuroci 2002;3:71-76.

-6 Márquez L, Olivares L: Epilepsia en México. Estudio epidemiológico de una comunidad rural. Salud Publica Mex 1979;21:487-495.

-7 Garcia-Pedroza F, Chandra V, Ziegler DK, Schoenberg B: Prevalence survey of headache in a rural Mexican village. Neuroepidemiology 1991;10:86-92.

-8 Morillo LE, Alarcon F, Aranaga N, Aulet S, Chapman E, Conterno L, Estevez E, GarciaPedroza F, Garrido J, Macias-Islas M, Monzillo P, Nunez L, Plascencia N, Rodriguez $\mathrm{C}$, Takeuchi $\mathrm{Y}$, Latin American Migraine Study Group: Prevalence of migraine in Latin America. Headache 2005;45:106117.

9 World Health Organization: Research Protocol for Measuring the Prevalence of Neurological Disorders in Developing Countries. Neuroscience Program. Geneva, World Health Organization, 1981.
10 Headache Classification Subcommittee of the International Headache Society: The International Classification of Headache Disorders: 2nd edition. Cephalalgia 2004;24:9-160.

11 Commission of Epidemiology and Prognosis, International League against Epilepsy: Guidelines for epidemiological studies on epilepsy. Epilepsia 1993;34:592-596.

12 World Health Organization: Recommendations on stroke prevention, diagnosis and therapy. Report of the WHO Task Force on stroke and other cerebrovascular disorders. Stroke 1989;20:1407-1431.

13 Bharucha NE, Bharucha AE, Bharucha EP: Prevalence of peripheral neuropathy in the Parsi community of Bombay. Neurology 1991;41:1315-1317.

14 Katusic SK, Beard CM, Wiederholt WC, Bergstralh EJ, Kurland LT: Incidence, clinical features, and prognosis in Bell's palsy, Rochester, Minnesota, 1968-1982. Ann Neurol 1986;20:622-627.

15 American Psychiatric Association: Diagnosis and Statistical Manual of Mental disorders, ed 4, revised. Washington, American Psychiatric Association, 2000.

16 Deuschl G, Bain P, Brin M: Consensus statement of the Movement Disorder Society on Tremor. Ad Hoc Scientific Committee. Mov Disord 1998;13:2-23.

17 Segi M: Cancer Mortality for Selected Sites in 24 Countries (1950-1957). Sendai, Department of Public Health, Tohoku University of Medicine, 1960.

18 Osuntokun BO, Adeuja AO, Schoenberg BS, Bademosi O, Nottidge VA, Olumide AO, Ige O, Yaria F, Bolis CL: Neurological disorders in Nigerian Africans: a community-based study. Acta Neurol Scand 1987;75:13-21.

$\checkmark 19$ Longe AC, Osuntokun BO: Prevalence of neurological disorders in Udo, a rural community in southern Nigeria. Trop Geogr Med 1989;41:36-40.
20 Al Rajeh S, Bademosi O, Ismail H, Awada A, Dawodu A, al-Freihi H, Assuhaimi S, Borollosi M, al-Shammasi S: A community survey of neurological disorders in Saudi Arabia: the Thugbah study. Neuroepidemiology 1993;12:164-178.

21 Saha SP, Bhattacharya S, Das SK, Maity B, Roy T, Raut DK: Epidemiological study of neurological disorders in a rural population of Eastern India. J Indian Med Assoc 2003; 101:299-304.

22 Pradilla A G, Vesga A BE, León-Sarmiento FE, GENECO: National neuroepidemiological study in Colombia (EPINEURO). Rev Panam Salud Publica 2003;14:104-111.

$\longrightarrow 23$ Gourie-Devi M, Gururaj G, Satishchandra P, Subbakrishna DK: Prevalence of neurological disorders in Bangalore, India: a community-based study with a comparison between urban and rural areas. Neuroepidemiology 2004;23:261-268

-24 Nicoletti A, Reggio A, Bartoloni A, Failla G, Sofia V, Bartalesi F, Roselli M, Gamboa H, Salazar E, Osinaga R, Paradisi F, Tempera G, Dumas M, Hall AJ: Prevalence of epilepsy in rural Bolivia: a door-to-door survey. Neurology 1999;53:2064-2069.

25 Nicoletti A, Sofia V, Giuffrida S, Bartoloni A, Bartalesi F, Bartolo ML, Fermo SL, Cocuzza V, Gamboa H, Salazar E, Reggio A: Prevalence of stroke: a door-to-door survey in rural Bolivia. Stroke 2000;31:882-885.

26 Del Brutto OH, Idrovo L, Santibáñez R, Díaz-Calderón E, Mosquera A, Cuesta F, Navas C: Door-to-door survey of major neurological diseases in rural Ecuador - the Atahualpa Project: methodological aspects. Neuroepidemiology 2004;23:310-316.

-27 Del Brutto OH, Idrovo L, Mosquera A, Navas C, Santibáñez R, Cuesta F, Díaz-Calderón E: Stroke in rural Ecuador: a three-phase, doorto-door survey. Neurology 2004;63:19741975. 
-28 Del Brutto OH, Santibáñez R, Idrovo L, Rodrìguez S, Díaz-Calderón E, Navas C, Gilman RH, Cuesta F, Mosquera A, Gonzalez AE, Tsang VC, García HH: Epilepsy and neurocysticercosis in Atahualpa: a door-todoor survey in rural coastal Ecuador. Epilepsia 2005;46:583-587.

29 El Tallawy HN, Farghaly WM, Rageh TA, Shehata GA, Metwaly NA, Abo Elftoh N, Hegazy AM, El Moselhy EA, Rayan I, Al Fawal BM, Abd Elhamed MA: Epidemiology of major neurological disorders project in $\mathrm{Al}$ Kharga district, New Valley, Egypt. Neuroepidemiology 2010;35:291-297.

>30 Edwards T, Scott AG, Munyoki G, Odera VM, Chengo E, Bauni E, Kwasa T, Sander LW, Neville BG, Newton CR: Active convulsive epilepsy in a rural district of Kenya: a study of prevalence and possible risk factors. Lancet Neurol 2008;7:50-56.
1 Senanayake N, Román GC: Epidemiology of epilepsy in developing countries. Bull World Health Organ 1993;71:247-258.

32 Burneo JG, Tellez-Zenteno J, Wiebe S: Understanding the burden of epilepsy in Latin America: a systematic review of its prevalence and incidence. Epilepsy Res 2005;66: 63-74.

33 Florez JC, Price AL, Campbell D, Riba L, Parra MV, Yu F, Duque C, Saxena R, Gallego N, Tello-Ruiz M, Franco L, Rodríguez-Torres M, Villegas A, Bedoya G, Aguilar-Salinas CA, Tusié-Luna MT, Ruiz-Linares A, Reich D: Strong association of socioeconomic status with genetic ancestry in Latinos: implications for admixture studies of type 2 diabetes. Diabetologia 2009;52:1528-1536.
4 Olaiz-Fernández G, Rojas R, Aguilar-Salinas CA, Rauda J, Villalpando S: Diabetes mellitus en adultos mexicanos. Resultados de la Encuesta Nacional de Salud 2000. Salud Publica Mex 2007;49:S331-S337.

35 Alonso E, Martínez-Ruano L, De Biase I, Mader C, Ochoa A, Yescas P, Gutiérrez R, White M, Ruano L, Fragoso-Benítez M, Ashizawa T, Bidichandani SI, Rasmussen A: Distinct distribution of autosomal dominant spinocerebellar ataxia in the Mexican population. Mov Disord 2007;22:1050-1053.

36 Rasmussen A, Gómez M, Alonso E, Bidichandani SI: Clinical heterogeneity of recessive ataxia in the Mexican population. J Neurol Neurosurg Psychiatry 2006;77:13701372. 